\title{
Inborn Errors of Immunity caused by defects of the DNA damage response pathways
}

\author{
Benjamin Fournier ${ }^{1}$, Nizar Mahlaoui ${ }^{1}$, Despina Moshous ${ }^{1}$, and Jean-Pierre DE \\ VILLARTAY ${ }^{2}$ \\ ${ }^{1} \mathrm{APHP}$ \\ ${ }^{2}$ IMAGINE
}

March 8, 2022

\begin{abstract}
Several inborn errors of immunity are caused by defects in the general DNA repair machinery as exemplified by the T-BRS-SCID condition owing to impaired resolution of programmed DNA double strands breaks introduced by RAG1/2 during $\mathrm{V}(\mathrm{D}) \mathrm{J}$ recombination. The genome instability generally associated with these conditions results in an increased propensity to develop malignancies requiring genotoxic based anti-cancer treatments. Moreover, the extent of immune deficiency often calls for hematopoietic stem cell transplantation as a definitive treatment, thus also demanding genotoxic based conditioning regimen prior to transplantation. In both cases, the underlying general DNA repair defects may result in catastrophic iatrogenic consequences. It is therefore of paramount importance to assess the functionality of the DNA repair apparatus prior to any genotoxic treatment when the exact molecular cause of the disease is unknown. For this purpose, two simple assays can be used on patient's derived peripheral blood lymphocytes. 1) The PROMIDIS $\alpha$ biomarker, based on the next generation sequencing analysis of the TCR $\alpha$ will highlight specific signatures of DNA repair deficiencies. 2) Direct analysis of the sensitivity of peripheral lymphocytes to ionizing radiations will formally identify patients at risk to develop toxicity towards genotoxic based treatments.
\end{abstract}

Inborn Errors of Immunity caused by defects of the DNA damage response pathways

Benjamin Fournier ${ }^{1}$, Nizar Mahlaoui ${ }^{1,2}$, Despina Moshous ${ }^{1,3}$, Jean-Pierre de Villartay ${ }^{3,4}$

1 Pediatric Hematology-Immunology and Rheumatology Department, APHP-Centre Université de Paris (CUP), Necker Hospital, F75015 Paris, France.

2 French National Reference Center for Primary Immune Deficiencies (CEREDIH), Necker Enfants Malades University Hospital, Assistance Publique-Hôpitaux de Paris (AP-HP), Paris, France;

3 Université de Paris, Imagine Institute, Laboratory "Genome Dynamics in the Immune System", INSERM UMR 1163, F-75015, Paris, France.

4 Equipe Labellisée Ligue Nationale Contre le Cancer, F75015 Paris, France.

Running title : Genotoxic treatments in SCID patients

Correspondence

Dr. Jean-Pierre de VILLARTAY

DGSI, Imagine Institute

24 bd du Montparnasse, 75015 Paris, France 
Email: Jean-Pierre.de-Villartay@inserm.fr

Word count: 4 355; 1 Table, 3 Figures

Fournier B., Mahlaoui N., Moshous D., and de Villartay J.P.

Inborn Errors of Immunity caused by defects of the DNA damage response pathways

Pediatr Allergy Immunol.

Abstract

Several inborn errors of immunity are caused by defects in the general DNA repair machinery as exemplified by the T-B- RS-SCID condition owing to impaired resolution of programmed DNA double strands breaks introduced by RAG1/2 during V(D)J recombination. The genome instability generally associated with these conditions results in an increased propensity to develop malignancies requiring genotoxic based anti-cancer treatments. Moreover, the extent of immune deficiency often calls for hematopoietic stem cell transplantation as a definitive treatment, thus also demanding genotoxic based conditioning regimen prior to transplantation. In both cases, the underlying general DNA repair defects may result in catastrophic iatrogenic consequences. It is therefore of paramount importance to assess the functionality of the DNA repair apparatus prior to any genotoxic treatment when the exact molecular cause of the disease is unknown. For this purpose, two simple assays can be used on patient's derived peripheral blood lymphocytes. 1) The PROMIDIS $\alpha$ biomarker, based on the next generation sequencing analysis of the TCR $\alpha$, will highlight specific signatures of DNA repair deficiencies. 2) Direct analysis of the sensitivity of peripheral lymphocytes to ionizing radiations will formally identify patients at risk to develop toxicity towards genotoxic based treatments.

Keywords

Class Switch Recombination, DNA damage and repair, Genotoxicity, RS-SCID, V(D)J Recombination

Key Message

DNA repair disorders are characterized by various degrees of immune deficiency sometimes necessitating hematological stem cell transplantation (HCT) and by an increased risk of developing solid tumors and/or hematological malignancies. As conditioning regimens prior to HSCT and anti-cancer treatments are often based on the use of strongly genotoxic genotoxic agents it is of paramount importance to evaluate the patients' radiosensitivity status prior to such treatments and adjust the posology accordingly as to avoid severe iatrogenic complications.

Correspondence

Dr. Jean-Pierre de VILLARTAY

DGSI, Imagine Institute

24 bd du Montparnasse, 75015 Paris, France

Introduction

Living organisms are constantly exposed to genotoxic assaults, which can be of endogenous origin, such as cellular respiration, or exogenous sources such as radiation or chemical exposure. Several highly conserved DNA repair mechanisms have been selected during evolution to cope with these various damages and maintain genomic integrity (1). Among DNA lesions, double-strand breaks (DSBs) are considered the most toxic. At least two main DNA repair pathways [homologous recombination (HR) and nonhomologous end joining (NHEJ)] have evolved to cope with DSBs. Nevertheless, the genome, carrier of our genetic information, is not static but instead subject to programmed modifications in several physiological circumstances. This is for example the case during meiosis, whereby DNA is rearranged through meiotic recombination, an essential molecular process that drives evolution. Likewise, the genome is heavily rearranged by the domesticated transposase piggyMac during the life cycle of ciliates. Lastly, the development and maturation of the 
adaptive immune system strictly relies on sequential somatic DNA rearrangement and modification steps through V(D)J recombination, Class switch recombination (CSR), and the generation of somatic hyper mutations (SHM) in immunoglobulin genes (2). Many of these DNA modification processes occur through the introduction of programmed DSBs (prDSBs) (3). Obviously, this is accompanied by very efficient DNA repair mechanisms, the defect of which are sources of various pathologies in humans and animal models.

Programmed DNA breaks in the immune system

the $\mathrm{V}(\mathrm{D}) \mathrm{J}$ recombination and T-B-SCIDs

The adaptive immune system is composed of $\mathrm{B}$ and $\mathrm{T}$ lymphocytes, which express large arrays of antigen specific receptors; the Immunoglobulin (Ig) or B cell receptor (BCR) on B lymphocytes and the T cell receptor (TCR) on $\mathrm{T}$ cells. The genes encoding the variable domains of these receptors are scattered along the chromosomes in distinct Variable (V), Diversity (D), and Joining (J) gene units (2). A tissue and stage specific DNA rearrangement process, the $\mathrm{V}(\mathrm{D}) \mathrm{J}$ recombination, results in the physical juxtaposition of one $\mathrm{V}, \mathrm{D}$, and J segment; thus forming the variable domain encoding exon. This mechanism, which is related to the "cut \& paste" transposition process, is initiated by the RAG1 and RAG2 lymphoid specific factors after recognition of Recombination Signal Sequences (RSS) that flank all V, D, and J elements to be rearranged and the introduction of DSBs at the border of the RSSs (4). Animal models of both RAG1 and RAG2 gene inactivation have unmistakably established the fundamental role of the $V(D) J$ recombination not only for the production of a diversified adaptive immune repertoire, but primarily for the complete developmental program of $\mathrm{B}$ and $\mathrm{T}$ lymphocytes. Likewise, human patients harboring biallelic RAG1/2 loss of function mutations are completely devoid of circulating mature $\mathrm{B}$ and $\mathrm{T}$ cells at birth, resulting in the condition T-BSevere Combined Immunodeficiency (T-B-SCID) (see Bosticardo et al. (5) for a recent review). Variations on the theme of T-B-SCID occurs depending on RAG1/2 mutations allowing residual activity and the emergence of $\mathrm{T}$ and $\mathrm{B}$ cell repertoires with various complexity. $\mathrm{V}(\mathrm{D}) \mathrm{J}$ recombination proceeds through the introduction of DSBs in G0/G1 arrested immature lymphocytes; pro-B in the bone marrow and pro$\mathrm{T}$ in the thymus. These prDSBs are repaired by the NHEJ apparatus, sole mechanism to cope with this type of DNA lesions within GO/G1 arrested cells. Faulty DSB repair caused by impaired NHEJ results in abortive $\mathrm{V}(\mathrm{D}) \mathrm{J}$ recombination and arrest of $\mathrm{B}$ and $\mathrm{T}$ cell development causing RS-SCID (6) (Table 1). In this instance, RS stems for radiosensitive as ubiquitous NHEJ deficiency results in a general DNA repair deficit that translates in an increased cellular sensitivity to genotoxic agents, such as ionizing radiation or radiomimetic drugs. The first example of RS-SCID was discovered in mice with the spontaneous appearance of the scid mutation, later found to affect the gene encoding the DNA-PK catalytic subunit (DNA-PKcs), one of the essential core NHEJ factors (7). Following, was the identification of the gene encoding the Artemis nuclease, mutated in human RS-SCID patients harboring similar phenotype as scid mice (8). Artemis not only constitutes an essential core NHEJ component for the repair of genotoxic introduced DSBs, it also exerts a unique function during $\mathrm{V}(\mathrm{D}) \mathrm{J}$ recombination through its endonuclease activity required for the opening of hairpin-sealed DNA ends specifically generated by the RAG1/2 domesticated transposase (9). Artemis is recruited to the RAG1/2 generated DSB by the Ku70-80/DNA-PK complex. As expected, patients harboring PRKDC (the gene encoding DNAPK-cs) deleterious mutations present with RS-SCID phenotype (10-12). The absence of Ku70/80 in animal models impairs the formation of the DNA-PK complex, resulting in a RS-SCID phenotype. However, Ku70/80 mutated human RS-SCID patients have not been identified so far, perhaps because these two factors are essential for cell viability in humans in contrast to mice. In the last step of $\mathrm{V}(\mathrm{D}) \mathrm{J}$ recombination the DNA ends are rejoined by DNA LigaseIV, one of the three eukaryotic DNA ligases, in association with its co-factors XRCC4 and Cernunnos/Xlf. DNA ligase IV or XRCC4 gene inactivation results in late embryonic lethality in mice, caused by apoptosis of post-mitotic neurons, and a RS-SCID phenotype in fetuses owing to an impaired V(D)J recombination (1315). In humans, the situation is a bit more complicated with a large spectrum of clinical presentations within the so-called "Lig4 syndrome", generally associated with developmental defects such as microcephaly and impaired immunity, depending on the underlying DNA ligase IV hypomorphic mutation (16-19). At one end of the clinical spectrum, Lig4 patients may even remain fully asymptomatic (no microcephaly, no immune deficiency) up to the point when they need to undergo genotoxic treatments for malignancies and 
develop acute toxicity, thus revealing their general DNA repair defect (20). The analysis of a series of phenotypical Lig4 patients without mutations in DNA Ligase IV revealed a new DNA repair encoding gene, Cernunnos, the defect of which results in microcephaly and immune deficiency characterized by a profound B and T cell lymphopenia (21). Cernunnos was independently identified as XRCC4 like factor (Xlf), given its sequence/structure homology with XRCC4 $(22,23)$. Quite surprisingly, despite their severe NHEJ deficiency illustrated by a profound sensitivity to genotoxic agents and an impaired $\mathrm{V}(\mathrm{D}) \mathrm{J}$ recombinationin vitro in non-lymphoid cells such as patients' fibroblasts (21) or murine MEFs and ES cells (24), Cernunnos/Xlf deficient condition is not associated with a major $\mathrm{V}(\mathrm{D}) \mathrm{J}$ recombination defect in vivo as shown by the lack of $\mathrm{B}$ and $\mathrm{T}$ cell specific maturation arrest in the bone marrow (BM) and thymus both in men (25) and mice $(26,27)$. Yet, suboptimal V(D)J recombination activity may participate in the phenotype (28). The apparent discrepancy between the severe in vitro NHEJ defect and the quite effective in vivo V(D)J recombination in Cernunnos/Xlf deficient condition highlighted the existence of a lymphoid specific backup system, which insures that RAG1/2 generated prDSBs are efficiently repaired, even in the absence of some core NHEJ factors (29). How the C-terminal region of RAG2 itself participates in this process is not yet fully understood. A tight coupling between the introduction of the DSBs and their repair by the NHEJ machinery may contribute to this backup system and may be generalized to other instances whereby prDSBs participate in physiological processes as during meiosis of programmed genome rearrangement in ciliates (3). According to this view, other human genetic diseases caused by general DNA repair defects may be exempt of consequences on the immune system. This is indeed the case for patients with hypomorphic deleterious mutations in the XRCC4 encoding gene. These patients mostly present short stature, microcephaly, and endocrine dysfunction (SSMED syndrome), but no profound alteration of the adaptive immune system, despite a severe NHEJ defect in vitro (30). The embryonic lethality and severe V(D)J recombination defect observed in XRCC4 KO mice, which phenocopy DNA ligase IV KO animals, is indeed mostly caused by the de facto destabilization of DNA Ligase IV. Other mutations that compromise the DNA repair function of XRCC4, such as its inability to participate in the XRCC4/Xlf filament (31-33), while sparing its critical function of DNA ligase IV stabilization, do not result in V(D)J recombination defects (34). Likewise, although the deficit in the DNA repair factor PAXX has no impact on the development of the immune system and no PAXX related diseases have been recognized so far, its likely participation during V(D)J recombination is highlighted by the block of B and T cell maturation in PAXX/Xlf doubly deficient mice (35-37).

Altogether, $\mathrm{V}(\mathrm{D}) \mathrm{J}$ recombination is essential for the proper development of the adaptive immune system. It proceeds through the introduction of "toxic" prDSBs but has most probably coopted specific backup systems to mitigate the potential oncogenic outcome of the reaction when not properly controlled. Therefore, while some patients with general DNA repair defects will develop RS-SCID, other conditions will remain asymptomatic with respect to the immune system. Yet, all these patients present a genuine risk of developing severe adverse effects in the course of genotoxic treatments during anti-cancer radio-chemotherapy or conditioning regimen prior to hematopoietic stem cell transplantation (HSCT), as discussed below.

The Class switch recombination (CSR); the somatic hypermutation (SHM) and the HIGM syndrome

During the terminal maturation of B lymphocytes the immunoglobulin genes undergo two additional somatic modifications of their DNA. The Class Switch Recombination (CSR) exchanges the previously Ig $\mu$ constant region encoding gene unit for a different downstream isotype $(\alpha, \gamma, \varepsilon)$ thereby modifying the effector function of the resulting antibody without altering its antigenic specificity. On the other hand, the process of Somatic Hypermutation (SHM) introduces mutations at hotspots within Ig variable encoding segments to increase the affinity of the resulting antibody. CSR and SHM are both triggered upon antigen recognition by B lymphocytes within germinal centers of secondary lymphoid organs (38). They are initiated by the Activation-Induced Cytidine Deaminase (AID), identified two decades ago $(39,40)$, with the primary goal to potentiate the humoral response against pathogens $(41,42)$. CSR relies mainly on the canonical NHEJ apparatus for the repair of the AID induced DSBs. Paradoxically, mutations introduced by AID during SHM are neither faithfully repaired by the Base Excision Repair (BER) nor the Mismatch repair (MMR) DNA repair pathways as they would be in any other cells of the body, but instead these pathways are diverted to purposely fix the introduced mutations. The molecular study of CSR highlighted several other peculiarities 
of DNA repair pathways co-opted by B lymphocytes during their terminal maturation. As an example, XRCC4 deficient conditions in mice highlighted the existence of a robust alternative DNA end joining pathway to cope with DSBs in the absence of the canonical NHEJ pathway $(43,44)$. This Alt-NHEJ mechanism during CSR makes use of abundant DNA sequence microhomology within switch regions $(\mathrm{S} \mu)$, thereby leaving a characteristic "footprint" at the CSR junction, which has been extensively studied in various human DNA repair conditions such as ATM deficiency in ataxia telangiectasia or Cernunnos/Xlf deficiency $(45,46)$. Another intriguing discovery in the context of CSR is the dissociation of function within the NHEJ factor 53BP1, which dissociates its DNA repair function from its role during CSR (47).

Molecular defects in CSR and SHM are responsible of a subset of "predominantly antibody deficiency" syndrome (PAD), previously designated as hyper IgM syndrome (HIGM). We will not discuss in depth the molecular basis of PADs since an extensive review has been very recently published (48). According to the authors, about $10 \%$ of CSR deficiencies are not yet attributed to a known molecular cause.

The extensive use of the in vitro CSR system provided by the IgM+ lymphoma cell line CH12F3 (49) has highlighted the function of several DNA repair factors during CSR. This is for example the case of the recently discovered shieldin complex (review in Setiaputra et al. (50)) or Fam72a identified through CRISPR/Cas9 genetic screens $(41,51)$. Although mutations in these factors have not been associated to PAD until now, they certainly represent serious candidate genes when all other known causes have been eliminated. Likewise, the use of the Human Gene Connectome (HGC) (52), which associates human gene pairs according to several possible biological paths, provides an interesting tool to contribute in the identification of disease causing mutations in new candidate factors as suggested by Amirifar et al. (48).

Other DNA repair defects in the hematopoietic system

In addition to defects in the core factors of the NHEJ apparatus that translate into SCID/CID manifestations described above, impairment of the general DNA damage response, notably during the phase of DNA damage signaling, often have consequences on the proper function of the hematopoietic system as a whole and the immune system in particular. This is also the case of the Nijmegen breakage syndrome (NBS) and ataxia telangiectasia (AT) caused by mutation in the NBN1 and ATM genes respectively (53). These two conditions are very similar and characterized by immunodeficiency, genome instability, and cancer predisposition. AT also includes progressive cerebellar degeneration. They are both characterized by a clinical radiosensitivity.

treatment of DNA repair defect associated immune deficiencies

Cancers

PIDs carry an increased risk of malignancy, particularly non-Hodgkin lymphoma (NHL) and skin cancers (54-56). Depending on the studies there was a 2-3-fold increased risk for all cancer types, 19.2-fold for leukemia and 11-fold for lymphoma (54); 1.42-fold increased risk for all cancer types, 10-fold for lymphoma and 4.55-fold for skin cancers but no increase for other types including leukemia (55).

Most of DNA repair-deficient patients are at much higher risk of malignancies, especially hematological malignancies when considering the important role of DSB repair during extensive cell proliferation, while extra-hematopoietic malignancies seem to be uncommon. As expected, core components of the DNA repair machinery are diverted by somatic events in several hematological malignancies in the general population, illustrating again their key role in $\mathrm{T}$ and $\mathrm{B}$ cell normal development (57).

The mechanisms leading to hematopoietic malignancies in DSB repair deficiency are multiple and intertwined (58): 1) defective immune surveillance (through $\mathrm{T}$ and $\mathrm{B}$ cell development disruption, defective lymphocyte proliferation and/or decreased diversity in the B and T-cell repertoire) may promote tumoral escape but also B-cell transformation and immortalization by EBV; 2) defects of DNA repair per se may induce point mutations, translocations and even chromotripsis (59) that represent oncogenic driver events and clonal selection in the context of a narrowed repertoire; 3) cell cycle defects and reduced apoptosis may favor cell survival. 
Defective immune surveillance is common to many PIDs, hence the increased rate of malignancies in DSB deficiency is underpinned by the $2^{\text {nd }}$ and third mechanism. The defect in EBV surveillance which infects only mature B cells (common to any T-cell defect) and the crucial role of NHEJ in T and B-cell development probably account for the selective lymphoma predisposition, especially NHL (60). Indeed, lymphoma and the premalignant lymphoproliferative diseases are often associated to EBV(.

Among DSB deficiencies, ataxia-telangiectasia and Nijmegen syndrome are extremely susceptible to malignancies, not only because these two factors play critical roles in sensing and signaling DSBs but also possibly because the immune deficiency being milder the affected patients do not require early definitive treatment by HSCT. ATM patients suffer from aggressive B-cell NHL, HL, pro-T acute lymphoid leukemia (ALL), B-ALL and more rarely carcinoma (median age: 12.5 years). Increased risk ratio of cancer is estimated at 56 -fold for all cancer types and can reach up to 570 -fold for NHL and 540-fold for HL $(62,63)$. Some patients endure second malignancies $(62,64)$. Heterozygous carriers have an increased risk of breast and digestive tract cancers (65).

Nijmegen syndrome has an extremely high risk of multiple malignancies, especially NHL. The incidence of cancer is reported to be $45 \%$, but reaches $71.6 \%$ after 20 years of age, while the incidence of second malignancy is $19 \%(64,66,67)$.

In LIG4 deficiency, about $24 \%$ of patients are reported with malignancy (based only on case reports). They develop NHL and acute leukemia (which always preceded aplasia, often precipitated by chemotherapy) $(19,68,69)$. Interestingly, the first reported patient with DNA ligase IV deficiency did not present any overt immunodeficiency until the age of 14 years, when he died due to an overresponse to radiotherapy for lymphoblastic leukemia .

XLF deficiency is very rare and it is thus difficult to assess the malignancy risk. One patient has been reported with EBV-negative lymphoma (70).

Malignancies have rarely been reported for Artemis-deficient patients, probably because most of them require HSCT for SCID before malignancy can develop. Consistently, they have been reported in CID patients with hypomorphic mutations and consisted in EBV+ lymphoproliferation and/or lymphoma (71-73). So far, no secondary malignancies post HSCT have been reported.

The best treatment to prevent cancer, relapse and secondary malignancies is HSCT, as developed below.

Chemotherapy remains the standard treatment but is complicated by severe toxicity due to the importance of the NHEJ pathway in all tissues. There are no definitive recommendations, but adapted chemotherapy protocols may include an initial reduced dose followed by dose escalation; full doses with increased time lapse between courses and/or replacement of selected cytotoxic agents with less toxic drugs (58). Complete remission remains the objective with such protocols $(63,66,67,74,75)$.

Numerous examples of extreme and often fatal toxicity of chemotherapy and radiotherapy are described $(58,74,76)$, including veno-occlusive disease and hepatitis, severe hemorrhagic cystitis, mucositis, infection and pulmonary failure. As the malignant disease may be the first sign of the DSB deficiency, it is of tremendous importance for clinicians to consider these underlying conditions to adjust the treatment. Clinical examination and medical history are essential (77), as well as laboratory tests as discussed below. If DSBdeficiency has been identified, screening recommendation for malignancies should be implemented .

The incidence of secondary cancers directly due to chemotherapy is difficult to evaluate, as prognosis of first malignancy is poor and prevents long-term follow up. Moreover, the DSB-deficiency may be sufficient for a second cancer to occur. However, the high rate of lymphoma as secondary cancer argues that secondary cancers are driven by the DSB-deficiency rather than by chemotherapy complications $(62,64,66,67)$.

Alternative treatments may include immunotherapy, based on targets identified on histology (such as CD30, PD-1, PD-L1 or CD38), especially in the contex of PID in which lymphoproliferative diseases may be hard to differentiate from overt lymphoma. Allogeneic CAR-T cells may be another option in the future. 


\section{Hematopoietic Stem cell transplantation}

Defects in DNA repair factors at the crossroad between developmental disorders and primary immune deficiencies (PID) generate a large spectrum of disease manifestations. The DNA Ligase IV syndrome is one of the most representative examples with patients presenting a phenotypic continuum associating microcephaly and/or immune deficiency and/or cancer predisposition. The deleterious effect on the immune system is very variable ranging from severe (SCID, CID) to milder forms (CVID, humoral immune deficiencies), as well as autoimmunity and immune dysregulation. Timely molecular diagnosis is challenging but of utmost importance for optimal patient care. Intrauterine growth retardation, microcephaly, facial dysmorphia, and/or developmental delay are clinical warning signs that should alert the physician to seek for a DNA repair deficiency as underlying cause for PID. However, these manifestations are not always present. For most of these PIDs allogenic HSCT remains the unique curative treatment option, although some academic gene therapy trials are currently developed.

So far, newborn screening for SCID is not yet routinely implemented, therefore most SCID patients are diagnosed in an infectious setting. Genetic testing may not be rapidly available and should not delay the initiation of curative HSCT, particularly in SCID patients with ongoing viral infections. Therefore, HSCT conditioning is often initiated prior to molecular diagnosis. As the DNA repair defect is ubiquitous, all cells are vulnerable to DNA damaging agents. Conditioning related toxicity is thus a major concern in DNA repair deficiencies contributing not only to transplantation related toxicity and mortality, but also to poorer quality of life post HSCT. Ideally, patients should be referred to reference centers experienced in these rare conditions. Patients present an increased risk for mucositis, veino-occlusive disease, pulmonary hypertension, thrombotic microangiopathy, as well as other transplant-associated endothelial cell activation syndromes, including capillary leak syndrome, engraftment syndrome, and idiopathic pneumonia syndrome. Other consequences may be infertility and secondary malignancies. Preexisting infections and chemotherapy induced tissue damage may

also increase the occurrence of graft versus host disease (GVHD). Specific recommendations for the use of appropriate chemotherapeutic protocols have been elaborated in order to overcome these limitations $(78,79)$, total body irradiation should not be used. The use of alkylating agents in ARTEMIS deficient T-B-Nk+ SCID patients was associated to a significantly higher occurrence of poor growth, abnormalities in dental development and endocrine late effects when compared to RAG1 or 2 deficient T-B-Nk+ SCID (80).

Unlike in HSCT for malignant hematological disorders, full donor chimerism is not an absolute prerequisite to cure PID, which opens the way for reduced intensity conditioning regimens leading in some patients to mixed chimerism. Although immune reconstitution is possible in the case of mixed chimerism, it has been shown that donor myeloid engraftment may ensure better long-term immune reconstitution, and thus ultimately improved quality of life (78). Optimal naive CD4 T lymphocyte regeneration as well as B cell reconstitution should be the aim.

Future precision medicine will require timely molecular diagnosis to design patient tailored conditioning according to the precise underlying DNA repair deficiency. In the meantime, tools like PROMIDIS $\alpha$ (se below) and assessment of patient's cells for increased sensitivity to irradiation or chemotherapeutical agents are very precious screening methods in order to detect an underlying DNA repair disorder not only in patients with overt PID, but also with lymphoid malignancies, in order to minimize treatment-related toxicities.

Functional and molecular diagnosis of DNA repair defect associated immune deficiencies

To avoid possible adverse effects of treatments either during conditioning prior to HSCT or for anti-cancer therapy it is of paramount importance to identify patients with possible DNA repair deficiencies whenever the underlying molecular cause of the disease remains unknown.

\section{TCR-V $\alpha 7$ and PROMIDIS $\alpha$}

The TCR $\alpha$ locus is unique in the sense that it proceeds through organized, sequential $\mathrm{V} \alpha \mathrm{J} \alpha$ rearrangement waves, starting with the most proximal $\mathrm{V} \alpha$ and $\mathrm{J} \alpha$ segments up to the more distal ones (Fig. 1A). Following 
each wave, the produced TCR is "tested" for its immune relevance and possible T cell positive selection. If not proficient, a new $\mathrm{V} \alpha \mathrm{J} \alpha$ rearrangement cycle is initiated, using upstream and downstream $\mathrm{V} \alpha$ and $J \alpha$ respectively. This process relies on 1) the fitness of thymocytes and 2) the $\mathrm{V}(\mathrm{D}) \mathrm{J}$ recombination efficacy. Circumstances in which one of these two condition is impaired will result in premature arrest of the recombination process and therefore translate in a bias of the TCR $\alpha$ repertoire in which the most distal $\mathrm{V} \alpha$ and $\mathrm{J} \alpha$ segments are underrepresented as seen in several human conditions such as RORC (81) or Cernunnos/Xlf (27) deficiency. Such TCR $\alpha$ bias can easily be identified by quantifying the frequency of TCR-V $\alpha 7$ expressing $\mathrm{T}$ cells (82). Indeed, TCR-V $\alpha 7$ represents the most upstream TCR-V $\alpha$ segment (TRAV1) and is therefore utilized during the last waves of VJ rearrangements. TCR-V $\alpha 7$ is expressed by CD161 positive mucosal associated invariant T cells (MAIT) as well as other conventional, CD161 negative, T cells. Although the frequency of MAIT cells can be highly variable, the frequency of conventional TCR-Va7+/CD161- T lymphocytes oscillates around 3-5\% in healthy controls. In sharp contrast, patients with $\mathrm{V}(\mathrm{D}) \mathrm{J}$ recombination and/or DNA repair deficiency almost completely lack TCR-V $\alpha 7+\mathrm{T}$ cells, even when hypomorphic mutations spare the development of $\mathrm{T}$ cells to some extent as shown for RAG2, Artemis, Lig4, and Cernunnos deficiency in Fig. 1B.

Bias in TCR $\mathrm{V} \alpha$ and $\mathrm{J} \alpha$ usage caused by $\mathrm{V}(\mathrm{D}) \mathrm{J}$ recombination and/or DNA repair deficiency can also be evaluated using PROMIDIS $\alpha$ (82). In this assay (Fig. 2 ) a subset of the TCR $\alpha$ repertoire covering proximal, median and distal segments is analyzed by multiplexed PCR followed by NGS and statistical analysis. The relative representation of $\mathrm{V} \alpha$ segment and their associated $\mathrm{J} \alpha$ define 9 parameters of the PROMIDISasignatures that are further implemented in a principal component analysis and hierarchical clustering. As shown in Fig. 2C, all the $\mathrm{V}(\mathrm{D}) \mathrm{J}$ recombination defective patients (RAG1/2 or RS-SCID) cluster in the same group, away from the collection of healthy controls and without overlap. Interestingly, AT patients harboring mutations in the ATM gene mostly cluster within a separate group, with very few overlap with the "VDJ deficient" patients. Interestingly, a couple of patients with NBS syndrome clustered with AT cases. PROMIDIS $\alpha$ thus provides a very robust tool for the early diagnosis of these particular DNA repair defect conditions and allows for the functional validation of several newly identified variant of unknown significance within the ATM gene.

Radiosensitivity assay on PBMCs

The most straightforward way to diagnose a condition of impaired DNA repair is to directly asses the cellular sensitivity to genotoxic agents such as ionizing radiation (IR). In the assay presented in Fig. 3, PBMC obtained from blood are subjected to increasing doses of IR, followed by activation through the TCR via CD3/CD28 beads. The aptitude of T cells to proliferate following 6 days in culture with IL2 is recorded and used as a proxy for their DNA repair capacity at time of IR. While healthy controls maintain an efficient proliferative capacity (around 70\% relative viability) upon 2 Gy IR, patients with ATM, Lig4, Artemis, and Cernunnos deficiency show a sharp decrease in their relative viability/proliferation ( $10 \%$ or less), arguing for their underlying DNA repair defect. The assay is particularly robust with almost no overlap between controls and patients. Consistent with the recessive mode of inheritance of AT, ATM+/- obligate carriers do not present an increased radiosensitivity, within the limits of the assay.

Conclusion

The consequences of DNA repair deficiencies on the hematological system in general and the immune system in particular cover a large spectrum of clinical and biological presentations, from complete alymphocytosis in pediatric cases of RS-SCID to less severe forms of combined immunodeficiency (CID) or autoimmunity, sometimes only revealed in adulthood, and cancer prone patients without overt immunodeficiency. As for other forms of solid tumors, DNA repair deficiency is strongly associated with the onset of hematological malignancies, the treatment of which through genotoxic agents can be accompanied with severe iatrogen adverse effects (20). The radiosensitive status of any patient undergoing such treatments should be evaluated as to avoid these pejorative outcomes. Likewise, any patient undergoing HSCT should be evaluated for a possible DNA repair defect and the conditioning regimen attenuated accordingly as to avoid catastrophic outcome following transplantation (83). 
Conflict of interest

The authors declare no conflict of interest.

Acknowledgments

Work in JPV's lab is supported by institutional grants from INSERM, Agence Nationale de la Recherche (ANR-13-PRTS-0004, 'Investissements d'avenir' program ANR-10-IAHU-01), Institut National du Cancer (INCa PLBIO 16-280) and caritative associations AT-Europe, Action for AT, and Ligue Nationale Contre le Cancer (Equipe Labellisée).

Author contributions

B. Fournier, D. Moshous and JP de Villartay equally contributed in writing-review and editing of the manuscript. N. Malhaoui followed ATM patients used in this study.

References

1. Sancar A, Lindsey-Boltz LA, Unsal-Kaçmaz K, Linn S. Molecular mechanisms of mammalian DNA repair and the DNA damage checkpoints. Annu Rev Biochem. 2004;73:39-85.

2. Dudley DD, Chaudhuri J, Bassing CH, Alt FW. Mechanism and control of V(D)J recombination versus class switch recombination: similarities and differences. Adv Immunol. 2005;86:43-112.

3. Betermier M, Borde V, de Villartay JP. Coupling DNA Damage and Repair: an Essential Safeguard during Programmed DNA Double-Strand Breaks? Trends Cell Biol. 2020 Feb;30 (2):87-96.

4. Jung D, Giallourakis C, Mostoslavsky R, Alt FW. Mechanism and control of V(D)J recombination at the immunoglobulin heavy chain locus. Annu Rev Immunol. 2006;24:541-70.

5. Bosticardo M, Pala F, Notarangelo LD. RAG deficiencies: Recent advances in disease pathogenesis and novel therapeutic approaches. Eur J Immunol. 2021 May;51 (5):1028-38.

6. de Villartay JP. Congenital defects in V(D)J recombination. Br Med Bull. 2015 Jun;114 (1):157-67.

7. Bosma MJ, Carroll AM. The SCID mouse mutant: definition, characterization, and potential uses. Annu Rev Immunol. 1991;9:323-50.

8. Moshous D, Callebaut I, de Chasseval R, Corneo B, Cavazzana-Calvo M, Le Deist F, et al. ARTEMIS, a Novel DNA Double-Strand Break Repair / V(D)J Recombination Protein, is Mutated in Human Severe Combined Immune Deficiency. Cell. 2001;105:177-86.

9. Ma Y, Pannicke U, Schwarz K, Lieber MR. Hairpin opening and overhang processing by an Artemis/DNAdependent protein kinase complex in nonhomologous end joining and V(D)J recombination. Cell. 2002 Mar $22 ; 108(6): 781-94$.

10. van der Burg M, Ijspeert H, Verkaik NS, Turul T, Wiegant WW, Morotomi-Yano K, et al. A DNA-PKcs mutation in a radiosensitive T-B- SCID patient inhibits Artemis activation and nonhomologous end-joining. J Clin Invest. 2009 Jan;119 (1):91-8.

11. Woodbine L, Neal JA, Sasi NK, Shimada M, Deem K, Coleman H, et al. PRKDC mutations in a SCID patient with profound neurological abnormalities. J Clin Invest. 2013 Jul;123 (7):2969-80.

12. Mathieu AL, Verronese E, Rice GI, Fouyssac F, Bertrand Y, Picard C, et al. PRKDC mutations associated with immunodeficiency, granuloma, and autoimmune regulator-dependent autoimmunity. J Allergy Clin Immunol. 2015 Jun;135 (6):1578-88 e5.

13. Barnes DE, Stamp G, Rosewell I, Denzel A, Lindahl T. Targeted disruption of the gene encoding DNA ligase IV leads to lethality in embryonic mice. Curr Biol. 1998 Dec 17;8 (25):1395-8. 
14. Frank KM, Sekiguchi JM, Seidl KJ, Swat W, Rathbun GA, Cheng HL, et al. Late embryonic lethality and impaired V(D)J recombination in mice lacking DNA ligase IV. Nature. 1998 Nov 12;396 (6707):173-7.

15. Gao Y, Ferguson DO, Xie W, Manis JP, Sekiguchi J, Frank KM, et al. Interplay of p53 and DNA-repair protein XRCC4 in tumorigenesis, genomic stability and development. Nature. 2000 Apr 20;404 (6780):897900.

16. Buck D, Moshous D, de Chasseval R, Ma Y, le Deist F, Cavazzana-Calvo M, et al. Severe combined immunodeficiency and microcephaly in siblings with hypomorphic mutations in DNA ligase IV. Eur J Immunol. 2006 Jan;36 (1):224-35.

17. Enders A, Fisch P, Schwarz K, Duffner U, Pannicke U, Nikolopoulos E, et al. A severe form of human combined immunodeficiency due to mutations in DNA ligase IV. J Immunol. 2006 Apr 15;176 (8):5060-8.

18. O’Driscoll M, Cerosaletti KM, Girard PM, Dai Y, Stumm M, Kysela B, et al. DNA ligase IV mutations identified in patients exhibiting developmental delay and immunodeficiency. Mol Cell. 2001 Dec;8 (6):117585 .

19. Staines Boone AT, Chinn IK, Alaez-Verson C, Yamazaki-Nakashimada MA, Carrillo-Sanchez K, GarciaCruz MLH, et al. Failing to Make Ends Meet: The Broad Clinical Spectrum of DNA Ligase IV Deficiency. Case Series and Review of the Literature. Front Pediatr. 2018;6:426.

20. Plowman PN, Bridges BA, Arlett CF, Hinney A, Kingston JE. An instance of clinical radiation morbidity and cellular radiosensitivity, not associated with ataxia-telangiectasia. Br J Radiol. 1990 Aug;63 (752):624-8.

21. Buck D, Malivert L, de Chasseval R, Barraud A, Fondaneche MC, Sanal O, et al. Cernunnos, a novel nonhomologous end-joining factor, is mutated in human immunodeficiency with microcephaly. Cell. 2006 Jan 27;124 (2):287-99.

22. Ahnesorg P, Smith P, Jackson SP. XLF interacts with the XRCC4-DNA ligase IV complex to promote DNA nonhomologous end-joining. Cell. 2006 Jan 27;124 (2):301-13.

23. Callebaut I, Malivert L, Fischer A, Mornon JP, Revy P, de Villartay JP. Cernunnos interacts with the XRCC4 x DNA-ligase IV complex and is homologous to the yeast nonhomologous end-joining factor Nej1. J Biol Chem. 2006 May 19;281 (20):13857-60.

24. Zha S, Alt FW, Cheng HL, Brush JW, Li G. Defective DNA repair and increased genomic instability in Cernunnos-XLF-deficient murine ES cells. Proc Natl Acad Sci U A. 2007 Mar 13;104 (11):4518-23.

25. van der Burg M, Gennery AR. Educational paper. The expanding clinical and immunological spectrum of severe combined immunodeficiency. Eur J Pediatr. 2011 May;170 (5):561-71.

26. Li G, Alt FW, Cheng HL, Brush JW, Goff PH, Murphy MM, et al. Lymphocyte-specific compensation for XLF/cernunnos end-joining functions in V(D)J recombination. Mol Cell. 2008 Sep 5;31 (5):631-40.

27. Vera G, Rivera-Munoz P, Abramowski V, Malivert L, Lim A, Bole-Feysot C, et al. Cernunnos deficiency reduces thymocyte life span and alters the T cell repertoire in mice and humans. Mol Cell Biol. 2013 Feb;33 (4):701-11.

28. Roch B, Abramowski V, Chaumeil J, De Villartay JP. Cernunnos/Xlf deficiency results in suboptimal V(D)J recombination and impaired lymphoid development in mice. Front Immunol. 2019;10:443.

29. Lescale C, Abramowski V, Bedora-Faure M, Murigneux V, Vera G, Roth DB, et al. RAG2 and XLF/Cernunnos interplay reveals a novel role for the RAG complex in DNA repair. Nat Commun. 2016;7:10529.

30. de Villartay JP. When natural mutants do not fit our expectations: the intriguing case of patients with XRCC4 mutations revealed by whole-exome sequencing. EMBO Mol Med. 2015 Jul;7 (7):862-4. 
31. Hammel M, Yu Y, Fang S, Lees-Miller SP, Tainer JA. XLF regulates filament architecture of the XRCC4.ligase IV complex. Structure. 2010 Nov 10;18 (11):1431-42.

32. Ropars V, Drevet P, Legrand P, Baconnais S, Amram J, Faure G, et al. Structural characterization of filaments formed by human Xrcc4-Cernunnos/XLF complex involved in nonhomologous DNA end-joining. Proc Natl Acad Sci U A. 2011 Aug 2;108 (31):12663-8.

33. Wu Q, Ochi T, Matak-Vinkovic D, Robinson CV, Chirgadze DY, Blundell TL. Non-homologous endjoining partners in a helical dance: structural studies of XLF-XRCC4 interactions. Biochem Soc Trans. 2011 Oct;39 (5):1387-92, suppl 2 p following 1392.

34. Roch B, Abramowski V, Etienne O, Musilli S, David P, Charbonnier JB, et al. A XRCC4 mutant mouse, a model for human X4 syndrome, reveals interplays with Xlf, PAXX, and ATM in lymphoid development. Elife. 2021 Sep 14;10.

35. Lescale C, Lenden Hasse H, Blackford AN, Balmus G, Bianchi JJ, Yu W, et al. Specific Roles of XRCC4 Paralogs PAXX and XLF during V(D)J Recombination. Cell Rep. 2016 Sep 13;16 (11):2967-79.

36. Hung PJ, Chen BR, George R, Liberman C, Morales AJ, Colon-Ortiz P, et al. Deficiency of XLF and PAXX prevents DNA double-strand break repair by non-homologous end joining in lymphocytes. Cell Cycle. 2017 Feb;16 (3):286-95.

37. Abramowski V, Etienne O, Elsaid R, Yang J, Berland A, Kermasson L, et al. PAXX and Xlf interplay revealed by impaired CNS development and immunodeficiency of double KO mice. Cell Death Differ. 2018 Feb;25 (2):444-52.

38. De Silva NS, Klein U. Dynamics of B cells in germinal centres. Nat Rev Immunol. 2015 Mar;15 (3):137-48.

39. Muramatsu M, Kinoshita K, Fagarasan S, Yamada S, Shinkai Y, Honjo T. Class switch recombination and hypermutation require activation-induced cytidine deaminase (AID), a potential RNA editing enzyme. Cell. 2000 Sep 1;102 (5):553-63.

40. Revy P, Muto T, Levy Y, Geissmann F, Plebani A, Sanal O, et al. Activation-induced cytidine deaminase (AID) deficiency causes the autosomal recessive form of the Hyper-IgM syndrome (HIGM2). Cell. 2000 Sep $1 ; 102(5): 565-75$.

41. Feng Y, Li C, Stewart JA, Barbulescu P, Desivo NS, Alvarez-Quilon A, et al. FAM72A antagonizes UNG2 to promote mutagenic repair during antibody maturation. Nature. 2021 Dec;600 (7888):324-8.

42. Methot SP, Di Noia JM. Molecular Mechanisms of Somatic Hypermutation and Class Switch Recombination. Adv Immunol. 2017;133:37-87.

43. Soulas-Sprauel P, Le Guyader G, Rivera-Munoz P, Abramowski V, Olivier-Martin C, Goujet-Zalc C, et al. Role for DNA repair factor XRCC4 in immunoglobulin class switch recombination. J Exp Med. 2007 Jul 9;204 (7):1717-27.

44. Yan CT, Boboila C, Souza EK, Franco S, Hickernell TR, Murphy M, et al. IgH class switching and translocations use a robust non-classical end-joining pathway. Nature. 2007 Sep 27;449 (7161):478-82.

45. Du L, Peng R, Bjorkman A, Filipe de Miranda N, Rosner C, Kotnis A, et al. Cernunnos influences human immunoglobulin class switch recombination and may be associated with B cell lymphomagenesis. J Exp Med. 2012 Feb 13;209 (2):291-305.

46. Pan-Hammarstrom Q, Lahdesmaki A, Zhao Y, Du L, Zhao Z, Wen S, et al. Disparate roles of ATR and ATM in immunoglobulin class switch recombination and somatic hypermutation. J Exp Med. 2006 Jan 23;203 (1):99-110.

47. Sundaravinayagam D, Rahjouei A, Andreani M, Tupina D, Balasubramanian S, Saha T, et al. 53BP1 Supports Immunoglobulin Class Switch Recombination Independently of Its DNA Double-Strand Break End 
Protection Function. Cell Rep. 2019 Aug 6;28 (6):1389-1399 e6.

48. Amirifar P, Yazdani R, Azizi G, Ranjouri MR, Durandy A, Plebani A, et al. Known and potential molecules associated with altered $\mathrm{B}$ cell development leading to predominantly antibody deficiencies. Pediatr Allergy Immunol. 2021 Nov;32 (8):1601-15.

49. Nakamura M, Kondo S, Sugai M, Nazarea M, Imamura S, Honjo T. High frequency class switching of an IgM+ B lymphoma clone CH12F3 to IgA+ cells. Int Immunol. 1996 Feb;8 (2):193-201.

50. Setiaputra D, Durocher D. Shieldin - the protector of DNA ends. EMBO Rep. 2019 May;20 (5).

51. Rogier M, Moritz J, Robert I, Lescale C, Heyer V, Abello A, et al. Fam72a enforces error-prone DNA repair during antibody diversification. Nature. 2021 Dec;600 (7888):329-33.

52. Itan Y, Casanova JL. Novel primary immunodeficiency candidate genes predicted by the human gene connectome. Front Immunol. 2015;6:142.

53. Shiloh Y. ATAXIA-TELANGIECTASIA AND THE NIJMEGEN BREAKAGE SYNDROME: Related Disorders But Genes Apart. Annu Rev Genet. 1997 Dec;31 (1):635-62.

54. Jonkers I, Lis JT. Getting up to speed with transcription elongation by RNA polymerase II. Nat Rev Mol Cell Biol. 2015 Mar 1;16 (3):167-77.

55. Mayor PC, Eng KH, Singel KL, Abrams SI, Odunsi K, Moysich KB, et al. Cancer in primary immunodeficiency diseases: Cancer incidence in the United States Immune Deficiency Network Registry. J Allergy Clin Immunol. 2018 Mar;141 (3):1028-35.

56. Maffeis M, Notarangelo LD, Schumacher RF, Soncini E, Soresina A, Lanfranchi A, et al. Primary Immunodeficiencies and Oncological Risk: The Experience of the Children's Hospital of Brescia. Front Pediatr. $2019 ; 7: 232$.

57. Valikhani M, Rahimian E, Ahmadi SE, Chegeni R, Safa M. Involvement of classic and alternative non-homologous end joining pathways in hematologic malignancies: targeting strategies for treatment. Exp Hematol Oncol. 2021 Nov 3;10 (1):51.

58. Bomken S, van der Werff Ten Bosch J, Attarbaschi A, Bacon CM, Borkhardt A, Boztug K, et al. Current Understanding and Future Research Priorities in Malignancy Associated With Inborn Errors of Immunity and DNA Repair Disorders: The Perspective of an Interdisciplinary Working Group. Front Immunol. 2018;9:2912.

59. Ratnaparkhe M, Hlevnjak M, Kolb T, Jauch A, Maass KK, Devens F, et al. Genomic profiling of Acute lymphoblastic leukemia in ataxia telangiectasia patients reveals tight link between ATM mutations and chromothripsis. Leukemia. 2017 Oct;31 (10):2048-56.

60. Attarbaschi A, Carraro E, Abla O, Barzilai-Birenboim S, Bomken S, Brugieres L, et al. Non-Hodgkin lymphoma and pre-existing conditions: spectrum, clinical characteristics and outcome in 213 children and adolescents. Haematologica. 2016 Dec;101 (12):1581-91.

61. Riaz IB, Faridi W, Patnaik MM, Abraham RS. A Systematic Review on Predisposition to Lymphoid (B and T cell) Neoplasias in Patients With Primary Immunodeficiencies and Immune Dysregulatory Disorders (Inborn Errors of Immunity). Front Immunol. 2019;10:777.

62. Dutzmann CM, Spix C, Popp I, Kaiser M, Erdmann F, Erlacher M, et al. Cancer in Children With Fanconi Anemia and Ataxia-Telangiectasia-A Nationwide Register-Based Cohort Study in Germany. J Clin Oncol Off J Am Soc Clin Oncol. 2022 Jan 1;40 (1):32-9.

63. Suarez F, Mahlaoui N, Canioni D, Andriamanga C, Dubois d'Enghien C, Brousse N, et al. Incidence, presentation, and prognosis of malignancies in ataxia-telangiectasia: a report from the French national registry of primary immune deficiencies. J Clin Oncol Off J Am Soc Clin Oncol. 2015 Jan 10;33 (2):202-8. 
64. Attarbaschi A, Carraro E, Ronceray L, Andrés M, Barzilai-Birenboim S, Bomken S, et al. Second malignant neoplasms after treatment of non-Hodgkin's lymphoma-a retrospective multinational study of 189 children and adolescents. Leukemia. 2021 Feb;35 (2):534-49.

65. van Os NJH, Roeleveld N, Weemaes CMR, Jongmans MCJ, Janssens GO, Taylor AMR, et al. Health risks for ataxia-telangiectasia mutated heterozygotes: a systematic review, meta-analysis and evidence-based guideline. Clin Genet. 2016 Aug;90 (2):105-17.

66. Bienemann K, Burkhardt B, Modlich S, Meyer U, Möricke A, Bienemann K, et al. Promising therapy results for lymphoid malignancies in children with chromosomal breakage syndromes (Ataxia teleangiectasia or Nijmegen-breakage syndrome): a retrospective survey. Br J Haematol. 2011 Nov;155 (4):468-76.

67. Sharapova SO, Pashchenko OE, Bondarenko AV, Vakhlyarskaya SS, Prokofjeva T, Fedorova AS, et al. Geographical Distribution, Incidence, Malignancies, and Outcome of 136 Eastern Slavic Patients With Nijmegen Breakage Syndrome and NBN Founder Variant c.657_661del5. Front Immunol. 2020;11:602482.

68. Luo X, Liu Q, Jiang J, Tang W, Ding Y, Zhou L, et al. Characterization of a Cohort of Patients With LIG4 Deficiency Reveals the Founder Effect of p.R278L, Unique to the Chinese Population. Front Immunol. 2021 Jan 1;12:695993.

69. Riballo E, Critchlow SE, Teo S-H, Doherty AJ, Priestley A, Broughton B, et al. Identification of a defect in DNA ligase IV in a radiosensitive leukaemia patient. Curr Biol CB. 1999 Jul 1;9 (13):699-702.

70. Patiroglu T, Akar HH, van der Burg M, Kontas O. A case of XLF deficiency presented with diffuse large B cell lymphoma in the brain. Clin Immunol Orlando Fla. 2015 Dec;161 (2):394-5.

71. Fevang B, Fagerli UM, Sorte H, Aarset H, Hov H, Langmyr M, et al. Runaway Train: A Leaky Radiosensitive SCID with Skin Lesions and Multiple Lymphomas. Case Rep Immunol. 2018;2018:2053716.

72. Moshous D, Pannetier C, Chasseval Rd R de, Deist Fl F le, Cavazzana-Calvo M, Romana S, et al. Partial $\mathrm{T}$ and $\mathrm{B}$ lymphocyte immunodeficiency and predisposition to lymphoma in patients with hypomorphic mutations in Artemis. J Clin Invest. 2003 Feb 1;111 (3):381-7.

73. Woodbine L, Grigoriadou S, Goodarzi AA, Riballo E, Tape C, Oliver AW, et al. An Artemis polymorphic variant reduces Artemis activity and confers cellular radiosensitivity. DNA Repair. 2010 Sep 4;9 (9):1003-10.

74. Pastorczak A, Szczepanski T, Mlynarski W, International Berlin-Frankfurt-Munster (I-BFM) ALL host genetic variation working group. Clinical course and therapeutic implications for lymphoid malignancies in Nijmegen breakage syndrome. Eur J Med Genet. 2016 Mar;59 (3):126-32.

75. Schoenaker MHD, Suarez F, Szczepanski T, Mahlaoui N, Loeffen JL. Treatment of acute leukemia in children with ataxia telangiectasia (A-T). Eur J Med Genet. 2016 Dec;59 (12):641-6.

76. Pollard JW. Trophic macrophages in development and disease. Nat Rev Immunol. 2009 Apr 1;9 (4):25970.

77. Sharma R, Lewis S, Wlodarski MW. DNA Repair Syndromes and Cancer: Insights Into Genetics and Phenotype Patterns. Front Pediatr. 2020;8:570084.

78. Lankester AC, Albert MH, Booth C, Gennery AR, Gungor T, Honig M, et al. EBMT/ESID inborn errors working party guidelines for hematopoietic stem cell transplantation for inborn errors of immunity. Bone Marrow Transpl. 2021 Sep;56 (9):2052-62.

79. Slack J, Albert MH, Balashov D, Belohradsky BH, Bertaina A, Bleesing J, et al. Outcome of hematopoietic cell transplantation for DNA double-strand break repair disorders. J Allergy Clin Immunol. 2018 Jan;141 (1):322-328 e10.

80. Schuetz C, Neven B, Dvorak CC, Leroy S, Ege MJ, Pannicke U, et al. SCID patients with ARTEMIS vs RAG deficiencies following HCT: increased risk of late toxicity in ARTEMIS-deficient SCID. Blood. 2014 
Jan 9;123 (2):281-9.

81. Okada S, Markle JG, Deenick EK, Mele F, Averbuch D, Lagos M, et al. Impairment of immunity to Candida and Mycobacterium in humans with bi-allelic RORC mutations. Science. 2015 Aug 7;349 (6248):60613.

82. Berland A, Rosain J, Kaltenbach S, Allain V, Mahlaoui N, Melki I, et al. PROMIDISalpha: A Tcell receptor alpha signature associated with immunodeficiencies caused by $\mathrm{V}(\mathrm{D}) \mathrm{J}$ recombination defects. J Allergy Clin Immunol. 2019 Jan;143 (1):325-334 e2.

83. Slatter MA, Gennery AR. Update on DNA-Double Strand Break Repair Defects in Combined Primary Immunodeficiency. Curr Allergy Asthma Rep. 2020 Jul 9;20 (10):57.

Figure legends

Figure 1: Determination of TCR-V $\alpha 7$ expressing T lymphocytes. A) organization of the TCR $\alpha$ locus and sequential waves of $\mathrm{V} \alpha \mathrm{J} \alpha$ rearrangement. TCR-V $\alpha 7 / \mathrm{CD} 161$ determination by FACS analysis

Figure 2: PROMIDIS $\alpha$ biomarker. A) Organization of the TCR $\alpha$ locus and position of PCR primers. B) Example of NGS sequencing result of TCR $\alpha$ libraries. C) Hierarchical clustering of PROMIDIS $\alpha$ signatures among patients and healthy controls

Figure 3: Radiosensitivity testing on PBMC

Table 1: NHEJ factors and the development of the immune system

\begin{tabular}{llll}
\hline & Mice & Humans & OMIM \\
\hline Ku70 (XRCC6) & RS-SCID & not found & $\# 152690$ \\
Ku80 (XRCC5) & RS-SCID & not found & $\# 194364$ \\
DNA-PKcs & Scid mice & RS-SCID & $\# 600899$ \\
(XRCC7, PRKDC) & RS-SCID & RS-SCID & $\# 605988$ \\
Artemis & HCLRE1C) & $\begin{array}{l}\text { Hypomorphic Lig4 } \\
\text { syndrome }\end{array}$ & $\# 601837$ \\
DNA ligase IV(Lig4) & $\varepsilon$ lethal & $\begin{array}{l}\text { Hypomorphic, SSMED* } \\
\text { no immune defect }\end{array}$ & $\# 616541$ \\
XRCC4 & $\varepsilon$ lethal & Lig4 syndrome & $\# 611290$ \\
Cernunnos/Xlf & mild immune defect & not yet described & $\# 616315$ \\
(NHEJ1) & No immune defect & & \\
PAXX & RS-SCID on Xlf KO & & \\
\hline
\end{tabular}

* SSMED: Short stature, microcephaly, and endocrine dysfunction 
Figure 1

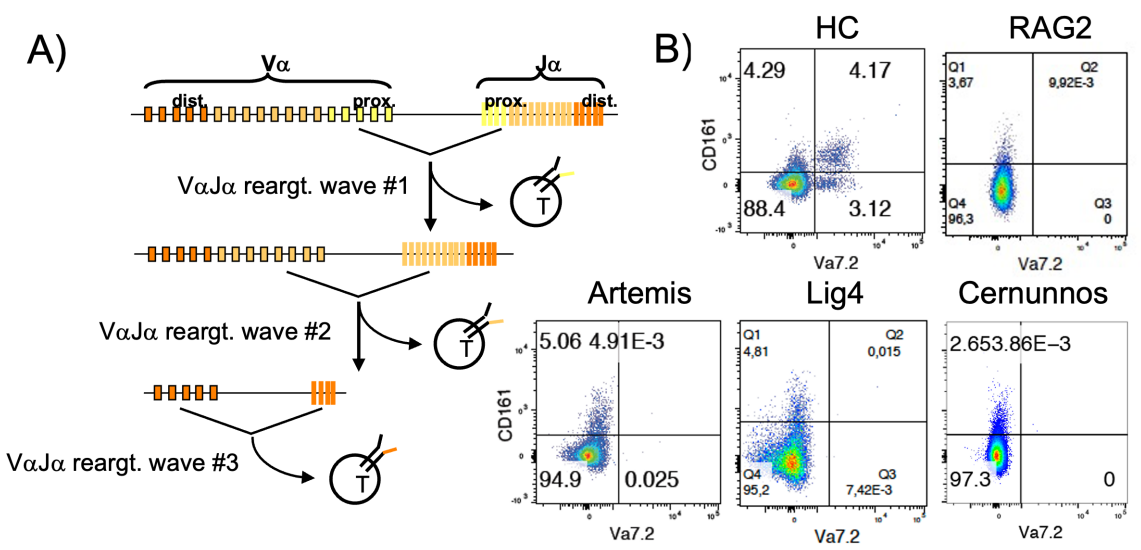


Figure 2

A)

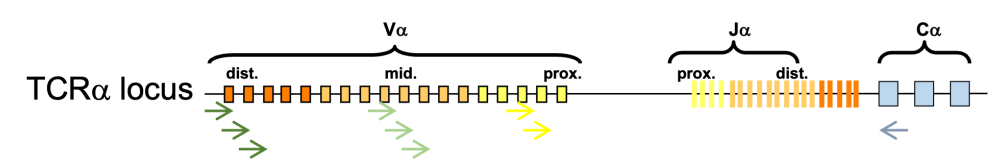

B)
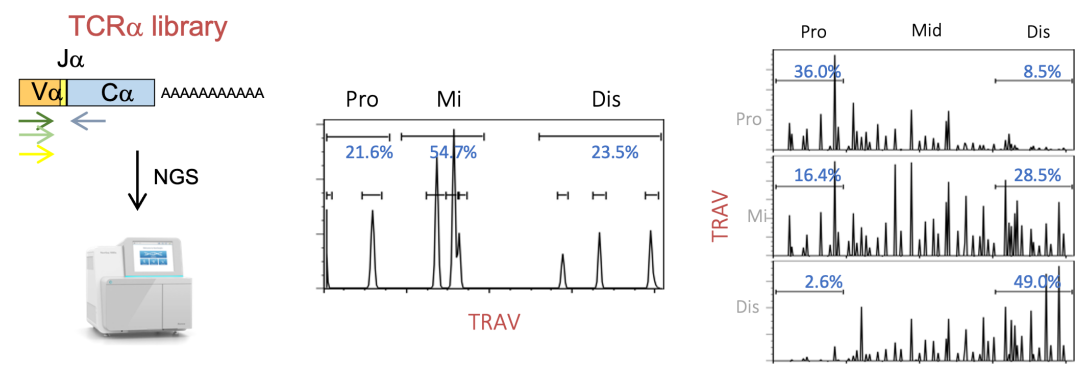

C)

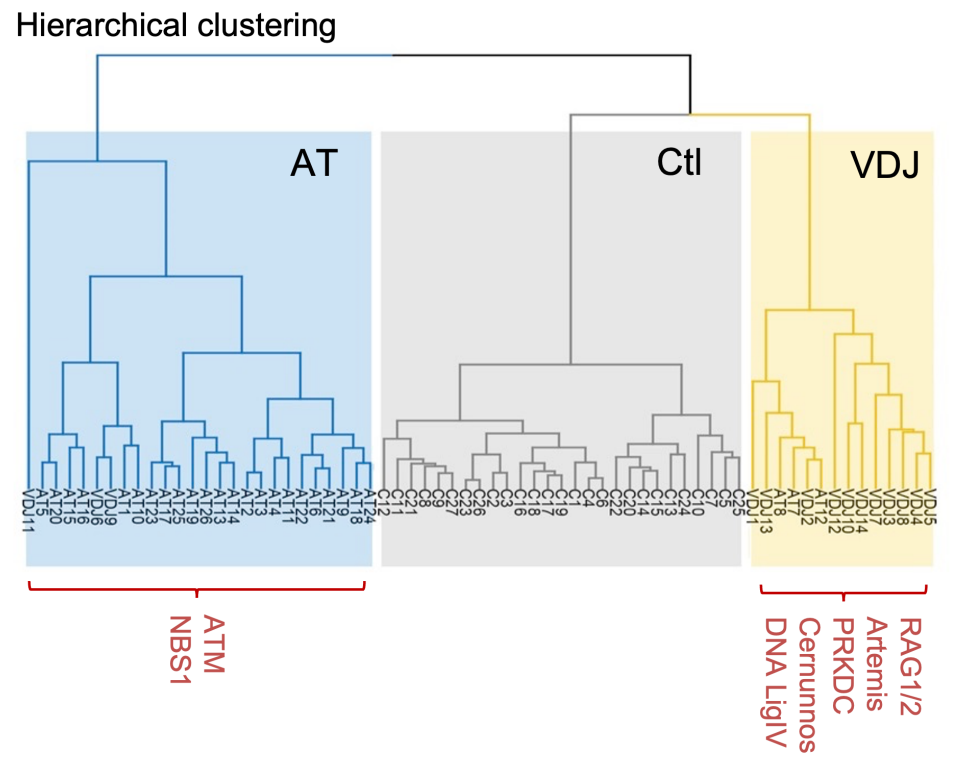


Figure 3

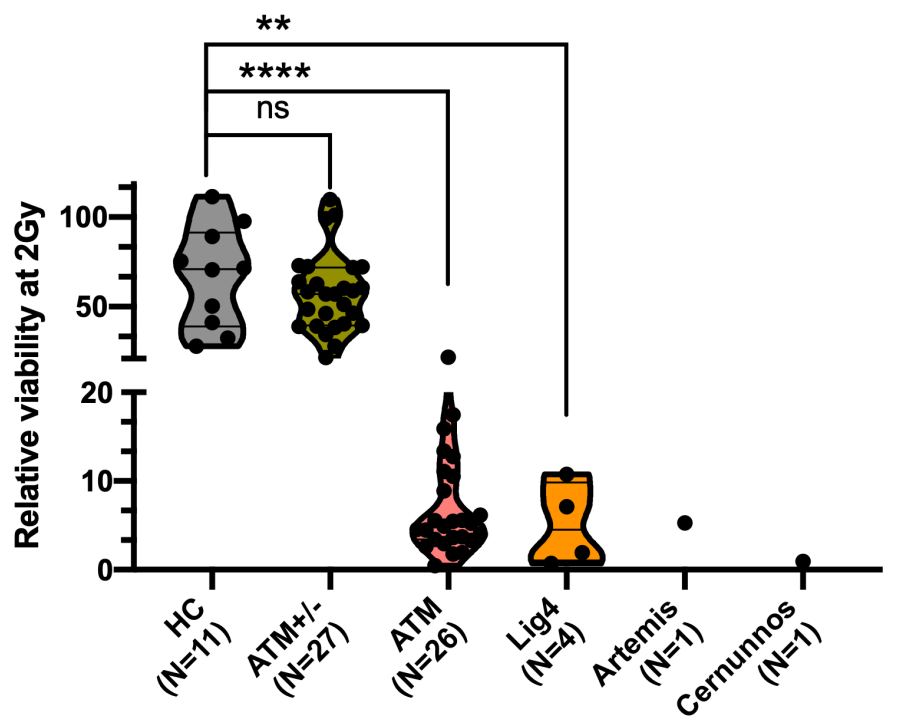

